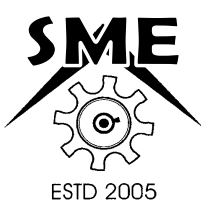

\title{
ANALYSIS OF BOILER BLOW DOWN PROCESS, AIR INGRESS IN CONDENSER AND EFFECT OF COAL MOISTURE IN 210 MW THERMAL POWER PLANT USING SIM SIMULATOR
}

\author{
*Mehul Chhowala ${ }^{1}$, Rahul Patel ${ }^{2}$ and Jaydeep Patel ${ }^{2}$
}

${ }^{1}$ Mechanical Engineering Department, Sarvajanik College of Engineering and Technology, Surat- 395001, India ${ }^{2}$ Mechanical Engineering Department, C. K Pithawala College of Engineering and Technology, Surat- 395001, India

\begin{abstract}
The Thermal Power plant contributes major proportion of installed capability in global power generation system as well as in Indian power generation systems. Therefore, achieving an optimal operation for the same, by conducting parametric study and optimizing few parameters which has a noticeable effect on the power generation may prove beneficial for plant efficiency. The simulation has been the tool for optimal operation and control of different variables in power plant. In addition, it also provides hands on experience to the trainee so that, they can have a better exposure of control room. In this part of the study, for the analysis purpose the SIM simulator (Standard Power Plant simulator) is being used which is comprehensive, dynamic and has a multi-fuel running ability employed with tandem-compound steam turbine-generator which is designed to operate at $210 \mathrm{MW}$. Moreover, it is also characterized by disturbances and malfunction features along with monitoring provision, which assists in parametric study and generates results in form of graphical representation to predict the effect of parameter on performance of power plant. Currently three parameters are chosen for further study. The effect of blow down process, Air leakage in condenser and coal moisture are selected.
\end{abstract}

https://doi.org/10.37255/jme.v15i1pp001-006

Keywords: Power Generation, SIM simulator and Air leakage.

\section{Introduction}

India's per capita energy and electricity consumptions are less than one tenth of developed countries' per capita consumption. India needs to make appropriate transform of our importance on conventional energy. Such a change in steps calls for a paradigm shift in our growth approach, i.e. from an unsustainable progress oriented economic development to an environmentally friendly impartial development. It is in our national and global interest that we reduce 'energy want' without eliminating the 'energy need' for a satisfactory quality of life. The globe has seen fastest expansion in energy demand, mostly satisfied by fossil fuels. Current energy scenario of India according to $\mathrm{BEE}$ as in below Table 1 which conclude maximum consumption of coal as a primary source of energy.

\section{1 Coal crisis}

Coal is accountable for meeting approximately half the energy requirements of the whole world. It plays an essential position in steel making, power generation and the manufacturing of cement. In developing countries such as India and China, coal is a preferred choice of fuel as it is the most affordable source of energy. About 80 percent of India's thermal power generation is based on coal. Coal is the principal energy source for power generation in India. Energy claim in India is estimated to boost over the next 10-15 years; although new oil and gas plants are considered, coal is likely to continue the leading fuel for power generation. Despite important rise in total installed capacity during the most recent decade, the space between electricity delivers and require continues to rise. The resulting deficit has had a pessimistic impact on industrial output and financial development.

Table 1 Primary Energy Consumption by Fuel

\begin{tabular}{|l|c|c|c|c|c|c|}
\hline Country & Oil & $\begin{array}{c}\text { Natural } \\
\text { Gas }\end{array}$ & Coal & $\begin{array}{c}\text { Nuclear } \\
\text { Energy }\end{array}$ & $\begin{array}{c}\text { Hydro } \\
\text { electric }\end{array}$ & Total \\
\hline USA & 914.3 & 566.8 & 573.9 & 181.9 & 60.9 & 2297.8 \\
\hline Canada & 96.4 & 78.7 & 31.0 & 16.8 & 68.6 & 291.4 \\
\hline France & 94.2 & 39.4 & 12.4 & 99.8 & 14.8 & 260.6 \\
\hline Russian Federation & 124.7 & 365.2 & 111.3 & 34.0 & 35.6 & 670.8 \\
\hline United Kingdom & 76.8 & 85.7 & 39.1 & 20.1 & 1.3 & 223.2 \\
\hline China & 275.2 & 29.5 & 799.7 & 9.8 & 64.0 & 1178.3 \\
\hline India & 113.3 & 27.1 & 185.3 & 4.1 & 15.6 & 345.3 \\
\hline Japan & 248.7 & 68.9 & 112.2 & 52.2 & 22.8 & 504.8 \\
\hline Malaysia & 23.9 & 25.6 & 3.2 & - & 1.7 & 54.4 \\
\hline Pakistan & 17.0 & 19.0 & 2.7 & 0.4 & 5.6 & 44.8 \\
\hline Singapore & 34.1 & 4.8 & - & - & - & 38.9 \\
\hline TOTAL WORLD & 3636.6 & 2331.9 & 2578.4 & 598.8 & 595.4 & 9741.1 \\
\hline & & & & &
\end{tabular}

*Corresponding Author - E-mail: mehul.chhowala@scet.ac.in 


\subsection{Power Plant Simulator}

The plant simulator is the replica of the control units running at given power plant. It provides an interface to execute the power plant operation on stipulated machine. Graphical interface, which allows the users to control or limit the execution of a command. Thermal power plant simulator is an effective tool for operational training used for safe, efficient and economical thermal power plant operation. Training with simulators provides comprehensive operator instruction for new personnel, while meeting the need to provide periodic refresher training and qualification for more experienced operators at the power plant.

The software has been developed by SIM Info systems Pvt. Itd. which is the Standard Power Plant simulator (PWR101U3) has a comprehensive, dynamic simulation of a coal/oil/gas-fired, tandem-compound steam turbine-generator power plant. It is designed to operate on a Simulation Solutions simulator (Figure 1), which consists of instructor functions and operational functions. The power plant consists of a natural circulation steam generator (boiler), uses pulverized coal/oil/gas for fuel, and has a tandem-compound turbine-generator rated at $210 \mathrm{MW}$.

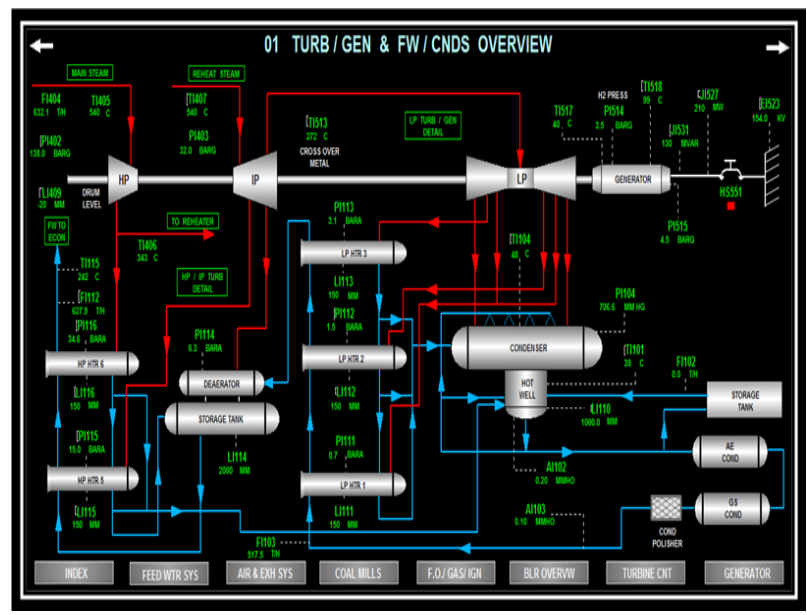

Fig. 1 Display console of SIM Simulator

\section{Literature Review}

Muhib Ali Rajper et al. [1] have performed thermodynamic study of $210 \mathrm{MW}$ dual-fires, subcritical, reheat steam power plant, located nearby Jamshoro, Pakistan. Initially, the plant is demonstrated by EES (Engineering Equation Solver) software. Furthermore; a parametric study is done to evaluate the effects of several operational factors on the performance. The net power output, energy efficiency and exergy efficiency are taken as performance variables of the plant whereas; condenser pressure, main steam pressure and main steam temperature are selected as operating parameters. According to the outcomes, the net power output, energy efficiency and exergy efficiency are defined as 186.5 MW, $31.37 \%$ and $30.41 \%$ respectively, under design operating situations. In a conclusion to the parametric study, deviation in operating variables had great impact on the plant performance.

Keerthi R Lekshmi et al. [2] have studied boiler blow down analysis and energy savings in an industrial establishment. Steam boilers need to be blow down to regulate the level of TDS in the boiler water. Feed water with a relatively low TDS level then replaces the discharge boiler water. The objective of this paper is the blow down analysis of 33TPH water tube boiler in the plant and analyse the annual savings obtained from the simple payback calculation.

Sunudas $\mathrm{T}$ et al [3] have studied optimization of boiler blow down and blow down heat recovery in textile area. Blow down process is important for the effectual operation of a boiler. To control the value of TDS in the boiler water optimal amount of blow down is executed at consistent intervals. With rise in the TDS value the scaling happens on boiler tubes and it cuts the boiler productivity and increases the boiler functioning cost. After the experimental readings it is revealed that almost $1.3 \%$ of fuel is wasted during blow down.

Jesse Colman [5] has studied the effect of ambient air and water temperature on power plant performance. The performance of thermoelectric generators be governed by a variety of factors, many of which are accurately controlled through generator design or operational management. However, there are environmental parameters that shake processes which cannot be controlled directly, such as air temperature and water temperature. This study develops practical approximations for the influence of air temperature and water temperature on the performance of coal and natural gas-fired power plants.

Hadyan Fahad Alajmi [6] has examined the effect of ambient air temperature on the steam rate (steam production). A parametric study was implemented based on exergy analysis to understand the effect of ambient air temperature on irreversibility, second law of efficiency and adiabatic flame temperature of steam production. The outcomes exposed that at $25 \%$ excess air and with the range of ambient air temperature from $25^{\circ} \mathrm{C}$ to $100^{\circ} \mathrm{C}$, the adiabatic flame temperature rises from $2015^{\circ} \mathrm{C}$ to $2065^{\circ} \mathrm{C}$. Also, the results presented that the second law efficiency and irreversibility ranges from $40.295 \%$ to $40.290 \%$ and 494.063 MJ to 494.161 MJ, respectively as the ambient air temperature rises from $25^{\circ} \mathrm{C}$ to $100^{\circ} \mathrm{C}$.It was determined that the ambient air temperature has a least 
influence on both combustion chamber and heat transfer sections.

Siddhartha Bhatt M. et al. [9] have studied influence of moisture in coal and fuel budget for indian thermal power plants. Indian coals hold low inherent moisture (IM) (5.5-9.5\% with an average of nearby $7.5 \%)$ and moisture addition is through the surface moisture (SM). Besides that, imported coals have very high IM (15-25\%) but minor SM. Existence of surface moisture (SM) is a main accountability for the power generating process and it's and control wants to be understood on a wider national viewpoint. Excessive significance must be specified during the transportation, handling, transfer and storage of coal to make sure that its heating value is well-maintained and there is no drop on account of SM addition reroute to the power plant or in the coal yard storage prior to its pass into the furnace of the boilers. It is the SM which has impact on the power plant operations.

Yannick Rousseau [10] has studied effect of climate change on thermal power station. The performance parameter and theoretical thermodynamic cycle efficiency connected to external variables such as atmospheric air temperature, flow rate and temperature of the coolant. The variation of these factors, mainly due to climate change, is estimated to negative impact on electrical power output of thermal power stations.

Mudita Dubey et al. [11] have analysed a 210 MW coal-based thermal power plant under operation in India. The complete power plant cycle is divided into three part for the study: (a) main steam system, (b) steam turbine, condenser, feed pumps and the HP and LP heaters, (c) the entire analysis with boiler, turbogenerator, condenser, feed pumps, regenerative heaters and the plant auxiliaries. It aids to discover the contributions of different parts of the power plant in the direction of energy destruction. Plant efficiency is estimated by the working data from the power plant at different circumstances, viz. at different loads, different condenser pressures, with and without regenerative heaters and with different sets of the turbine governing.

R.Paul et al. [14] have studied210 MW pulverized coal fired thermal power plantto search the potentials of renovation and modernization (R\&M) opportunities in an existing plant. Three different alternatives along with its cost suggestions have been discussed based on the performance and levelised cost of power generation. The outcome shows that with the $\mathrm{R} \& \mathrm{M}$ approach the unit availability can be rise to more than $85 \%$, with a capacity enhancement of $215 \mathrm{MW}$ and the heat rate of the unit will be around $2544 \mathrm{kcal} / \mathrm{kWh}$.

\section{The Effect of Blow Down Process on Various Parameter in Sim Simulator}

\subsection{Blow-down process}

As steam is produced, water is vaporised in its pure form leaving all of the dissolved minerals behind. Steam is fundamentally distilled water. The feed water which is supply to retain the boiler water level has a lesser concentration of chemicals and dilutes the chemical concentrations that develop during steam generation. Even with cautious boiler water treatment controlling, water or a water/steam mixture must be periodically released from the boiler to remove particulates and sludge and to regulate water chemical treatment concentrations in boiler. This process which is purposefully carried out is mention as boiler blow down process. The rate of blow down process can vary from less than $1 \%$ when very high-quality feed water is supplied to more than $20 \%$ in a system with poorquality feed water. The quantity of water to be blow down will be subject to the dissolved solids incoming to the boiler through the feed water [3].

Thus, factors that are most often observed to confirm the quality of steam are TDS and conductivity, $\mathrm{pH}$, silicates and phosphates concentration. The boiler blows down process is performed to reduce these levels and keep controlled to a point where the steam quality is not likely to be affected. A considerable amount of heat energy is vanished during blow down process [3].

\subsection{Parametric study of blow down process in SIM Simulator}

In this part of the study, different graphs are obtained by taking blow down range in the percentage range of $1 \%$ to $10 \%$.From figure 2 to figure 5 as the $\%$ of blow down increases it increases the removal rate of impurities with water from the drum and due to that there is reduction in the mass flow rate of steam subsequently, declining the network output and ultimately results in reduction of power generation. The water level in the drum reduces as the water is deliberately wasted to remove the sludge. So, the downward trend observed in the graph. Here decrease in drum pressure at different blow down ranges from $1 \%$ $10 \%$ was also noted. Due to opening the blow down valve there is loss of pressure for maintains the equilibrium and due to that reason, it reduces gradually. As the water is wasted intentionally to carry out the blow down process to compensate the flow rate, the feed water flow rate increases which can be closely observe from the graph. For the $1 \%$ blow down rate feed water flow rate is comparatively less than the $10 \%$. 


\subsection{The Benefits of Blow down Process in a}

\section{Thermal Power Station}

i. It cleans out solids that accumulate in the bottom of the boiler.

ii. Keeping the boiler water within the specification limits will improve the efficiency and the steam quality and as a result will reduce the boiler maintenance.

iii. Saves manual supervision for other tasks (with automatic control).

iv. Less water, fuel and treatment chemicals needed.

v. It prevents scale formation in boiler

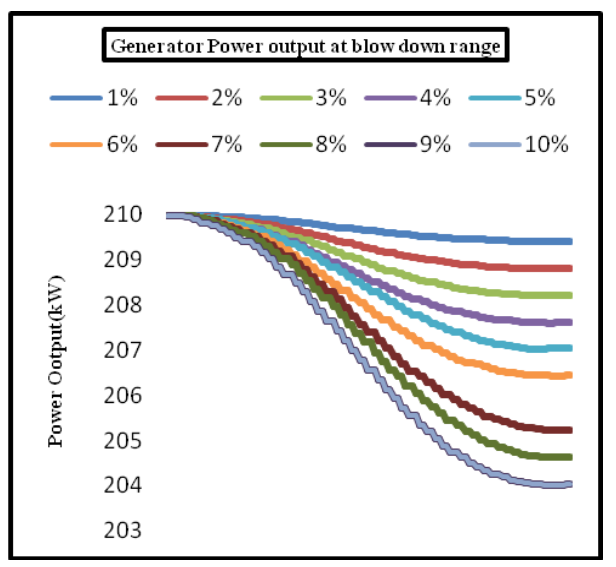

Fig. 2 Percentage of blow down Vs Generator

power $\mathbf{o} / \mathbf{p}$

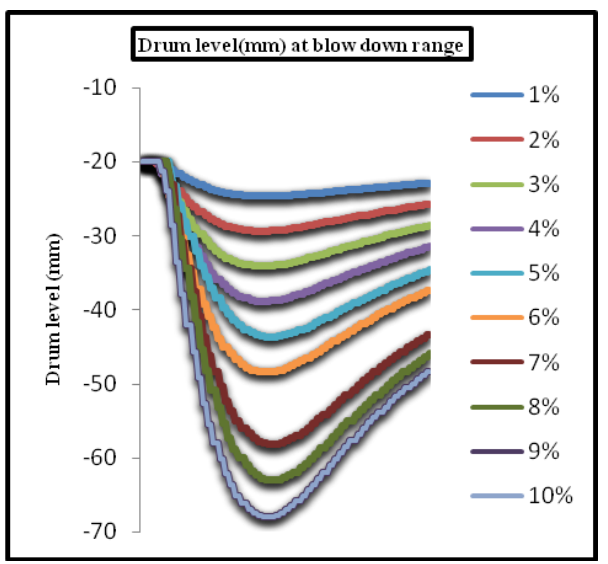

Fig. 3 Percentage of blow down Vs Drum level

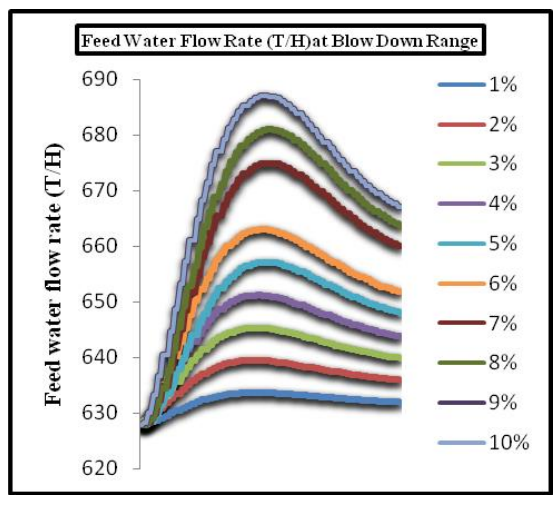

Fig. 4 Percentage of blow down Vs Feed water flow $\operatorname{rate}(\mathrm{T} / \mathrm{H})$

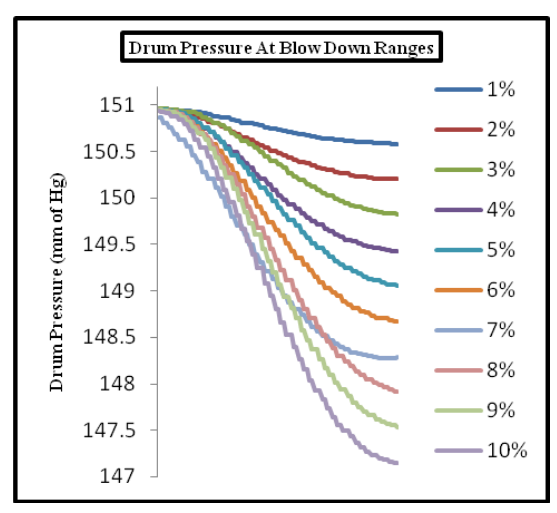

Fig. 5 Percentage of blow down Vs Drum pressure (bar)

\section{The Effect of Condenser Air Ingress \\ on Various Parameter in Sim Simulator}

In steam turbine-based power plant the basic principle of power generation is Rankine cycle. When the steam exits from the last stage of steam turbine, it becomes low pressure and low temperature wet steam. Condenser converts this low-pressure wet steam in to water, which is then feed to the boiler to continue the cycle. 
Condenser performance can be influenced by a wide range of factors such as air in-leak, vacuum equipment capacity, air venting efficacy, other factors related to plant operating conditions. Air ingress to condenser has adverse effect on plant performance and equipment life. High air in leakage can increase condenser back pressure, which leads to the reduction of efficiency and power out of turbine. In addition to that air ingress increases the dissolved oxygen in the cycle, which in turn reduces life of equipment.

\subsection{Simulating the effect of air infiltration in condenser}

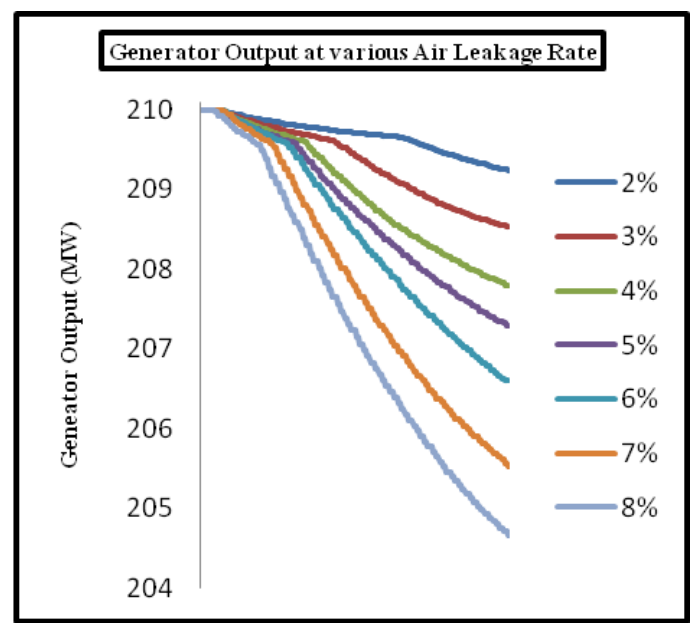

Fig. 6 Percentage of Air ingress Vs Generator power $\mathbf{o} / \mathbf{p}$

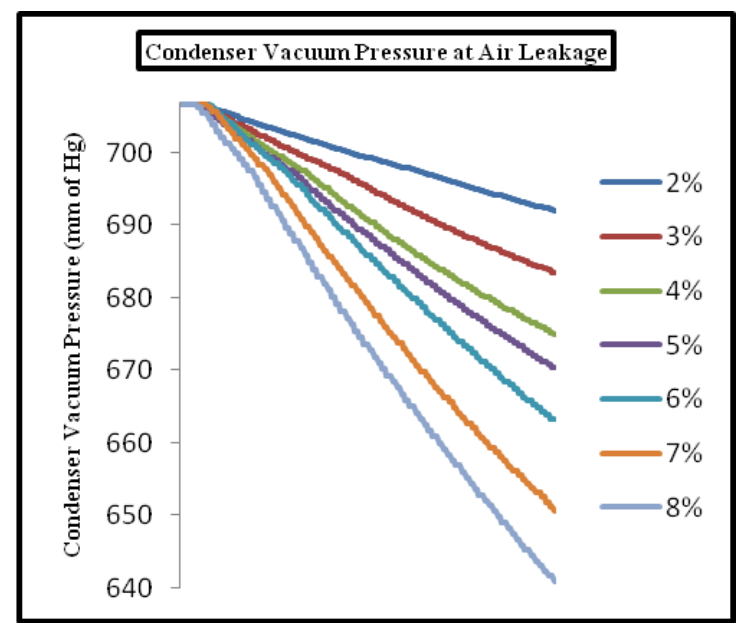

Fig. 7 Percentage of Air ingress Vs Condensor vaccum pressure ( $\mathrm{mm}$ of $\mathrm{Hg}$ )
From figure 6 and figure 7, it can be observed that the gradual decline for some period followed by more decrement. Because as air enters the condenser due to difference of the pressure, the vacuum maintained in the condenser decreases due to which there is rise in pressure of the condenser which subsequently reduces the output as network output reduces. Here downward trend in the second graph of Condenser Vacuum at different air leakage rates ranging from $2 \%$ to $8 \%$. The condenser vacuum reduces gradually due to ingress of air in the condenser. So, the vacuum pressure maintained in the condenser reduces results, increase in the pressure of the condenser.

\section{The Effect of Fuel (Coal) Moisture \\ on Various Parameter in Sim Simulator}

There are many effects of fuel moisture on unit operation, performance and emissions. As fuel moisture content decreases, its heating value increases and, assuming constant electric power output of a power plant, less coal needs to be fired. This reduces the burden on the coal handling system, conveyers and crushers. Also, since dryer coal is easier to convey, this reduces maintenance costs and increases availability of the coal handling system.

With drier coal, the flame temperature is higher due to less moisture evaporation. Because of flame temperature, the temperature of the coal ash particles is higher which could increase furnace fouling and slagging. Deposition of slag on furnace walls reduces heat transfer and results in a higher flue gas temperature at the furnace exit.

\subsection{Analysis of coal surface moisture in SIM Simulator}

As observed from figure 8 and figure 9, the generator output trend to show considerable decrement as the rate of coal moisture increases. In case of $5 \%$ moisture nearly $200 \mathrm{MW}$ power output is achieved. Similarly, for $10 \%$ \& $15 \%$ coal moisture power output is witnessed to be approximately 192 MW\& $182 \mathrm{MW}$ respectively. Since, heat required to overcome moisture in fuel results into declining nature of above graph. Overall, it can be clearly seen, the downward trend in graph of steam flow rate versus coal moisture rate. As moisture content in coal increases the heat required for steam generation is utilized for overcoming the moisture in fuel which eventually leads to reduction of steam flow rate. It is apparent that $20 \%$ coal moisture conduce approximately $540 \mathrm{~T} / \mathrm{H}$ which is recorded as minimum value in the given graph. 


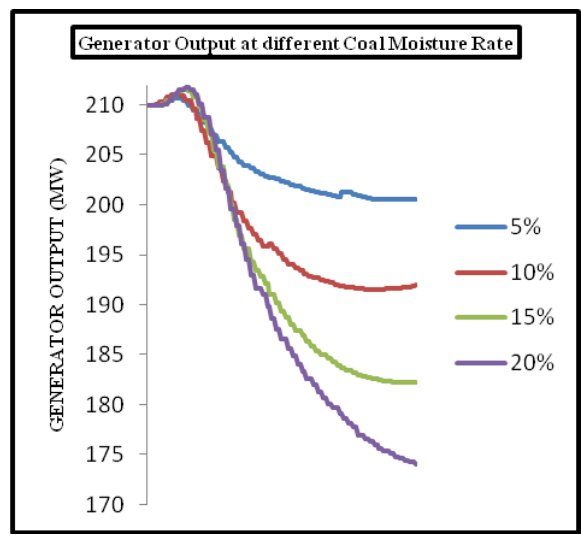

Fig. 8 Percentage of Coal moisture Vs Generator power

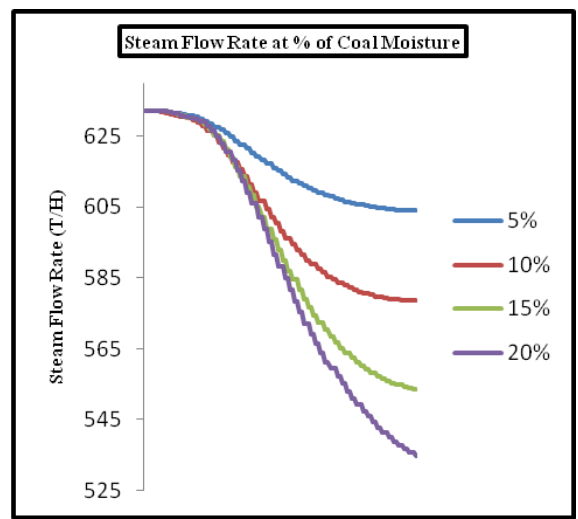

Fig. 9 Percentage of Coal moisture Vs main Steam flow $\operatorname{rate}(\mathrm{T} / \mathrm{H})$

\section{Conclusion}

The following conclusions are derived after doing parametric study by altering the data in given simulation software which is described below:

The deliberately carried out blow down apparently reduces the power output and heat rate considerably however it improves the plant life. Besides that, feed water flow rises dramatically whereas, drum level and drum pressure show declining nature.

The air ingress in condenser likely reduces the efficiency of condenser and has a moderate effect on power generation. Again, it plunges condenser vacuum pressure significantly as air leakage rate increases.

The moisture content in coal ought to be lower or the loss of heat can be evident in overcoming it. Also, the steam flow rate reduces as the percentage of moisture content in coal raises.

\section{Future work}

The thermal power station consists of end number of parameters which play a vital role in efficient operation, since in this part of study only three parameters which have a considerable effect on power generation. So other parameters such as number of feed water heater, number of re-heaters, atmospheric pressure, combine fuel firing etc. can be studied with comprehensive results however, it might prove laborious and tedious as well.

Besides that, an optimization can also be carried out by feeding the actual experimental data of any equivalent power plant in order to create analogy between trends of results in form of graph. However, the real time data cannot be feed in the software owing to improper functioning and unreliable results generation.

\section{References}

1. Muhib Ali Rajper, Abdul Ghafoor Memon and Khanji Harijan (2015), "Energy and Exergy Analysis of $210 \mathrm{MW}$ Jamshoro Thermal Power Plant", Mehran University Research Journal of Engineering and Technology (2016), Vol 35(3) 459-472.

2. Keerthi R Lekshmi and Vandana S Pillai (2015), "Boiler Blowdown Analysis inan Industrial Boiler", IOSR Journal of Engineering (IOSRJEN), Vol. 05(07); 22-28.

3. Sunudas T and M G Prince (2013), "Optimization of Boiler Blowdown and Blowdown Heat Recovery in Textile Sector", Int. Journal of Engineering Research and Applications, Vol. 3(5); 35-38

4. Jesse Colman (2013), "The Effect of Ambient Air and Water Temperature on Power Plant Efficiency", Master's project, Duke University.

5. Hadyan Fahad Alajmi (2017), "Effect of Ambient Air Temperature on the Performance of Steam Generator", International Journal of Environmental Science and Development, Vol. 8(7)

6. Siddhartha Bhatt $M$ and Rajkumar $N$ (2015), "Effect of Moisture in Coal on Station Heat Rate and Fuel Cost for Indian Thermal Power Plants", the Journal of CPRI, Vol. 11(4); 773-786

7. Yannick Rousseau (2013), "Impact of Climate Change on Thermal Power Plants", Case Study of Thermal Power Plants in France, Master's thesis, University of Iceland.

8. Mudita Dubey and Abhay Sharma (2012), "Improving The Efficiency Of Thermal Equipments Of $210 \mathrm{Mw}$ Tps Through Thermal Audit", International Journal of Advanced Research in Computer Engineering \& Technology, Vol. 1(5)

9. Paul $R$ and Pattanayak L (2014), "Performance Improvement of Pulverized Coal Fired Thermal Power Plant: A Retrofitting Option", International Journal of Engineering and Science, Vol.4(9); 05-13 